\title{
Acute pure sensory neuropathy
}

INSERM

\section{Source}

INSERM. (1999). Orphanet: an online rare disease and orphan drug data base. Acute pure sensory neuropathy. ORPHA:231450

Acute pure sensory neuropathy is a rare, acquired, demyelinating neuropathy disease characterized by acute, symmetric, monophasic sensory neuropathy without motor involvement, typically manifesting with numbness in the distal lower limbs which progressively extends to all the limb, ting ling sensation in the distal lower limbs, generalized areflexia, and unsteady gait, as well as clumsiness of the upper limbs, pseudoathetosis and loss of vibration sense. 